\title{
C|flestato
}

\section{Gestão da informação e mídias sociais para o engajamento dos estudantes nas instituições de ensino superior}

\author{
Everaldo Henrique dos Santos Barbosa \\ Doutorando; Universidade Estadual Paulista, Marília, SP, Brasil; \\ ehs.barbosa@unesp.br ORCID: http://orcid.org/0000-0001-7032-7584 \\ Cássia Regina Bassan de Moraes \\ Doutora; Universidade Estadual Paulista, Marília, SP, Brasil; \\ crbassan@gmail.com ORCID: http://orcid.org/0000-0001-6285-5117
}

\begin{abstract}
Resumo: Os dados e informações presentes nas mídias podem ser processados, interpretados e analisados, identificando métricas que demonstrem o nível de engajamento dos usuários. Podem, ainda, promover o engajamento de atuais e futuros estudantes nas instituições de ensino superior. Assim, o problema de pesquisa é: quais estratégias de conteúdo contribuem para o engajamento nas mídias sociais dos atuais e futuros estudantes? O objetivo geral consistiu em identificar as estratégias de conteúdo mais apropriadas para o uso das mídias sociais no engajamento dos estudantes. Os objetivos específicos são identificar qual tipo de conteúdo existente nas mídias sociais desperta mais atenção do público e investigar as medidas que permitem verificar informações do comportamento dos estudantes. Esta pesquisa se caracteriza como exploratória e de natureza quantitativa-descritiva, sendo utilizado o método Estudo de Caso de Yin (2010) realizado em uma instituição de ensino superior do estado de São Paulo, Brasil. Os sujeitos da pesquisa envolvem 109 estudantes e dois funcionários responsáveis pelas mídias sociais. Foi construído um quadro direcionador a partir da inter-relação dos conceitos de Gestão da Informação e mídias sociais, gerando indicadores para o uso das mídias sociais. O perfil social da instituição no Facebook, possui 4.932 usuários e 246 publicações para um intervalo de um mês. Foram observados os sinais de engajamento dos usuários e constatadas as publicações do tipo foto como as que mais obtiveram envolvimento. O período de vestibular representa maior fluxo de publicações. Além disso, $82,6 \%$ dos internautas afirmaram que se sentem mais próximos da instituição.
\end{abstract}

Palavras-chave: Brasil; Engajamento em mídias; Gestão da informação; Mídias sociais; Redes sociais. 


\section{Introdução}

As redes sociais presentes nas mídias estão cada vez mais evidentes na sociedade. As instituições acabam acompanhando, necessariamente, as tendências da comunicação digital e galgando objetivos de envolvimento com o público nas Mídias Sociais (MS). Assim, a legitimação das instituições de ensino está no quesito de aderir ao sistema midiático e incorporar-se socialmente para melhor desempenho de suas funções. Nesse sentido, o engajamento dos estudantes pode ser expresso por uma interação, conversa, envolvimento com a instituição de ensino, participação ou outra forma de ação, sendo on-line ou offline e por meio das MS (PERREAULT, 2017). As MS são compostas por redes interligadas por meio da internet, resultando em conexões de dados que são transmitidas geograficamente em caráter mundial (CASTELLS, 2012).

No século XXI, as redes passaram a ser classificadas em escalas de diferentes níveis. As redes internas e as externas, sendo as redes locais internas (Intranet), redes digitais sociais externas (Facebook, Instagram, Twitter, LinkedIn, entre outras), a rede digital social externa e específica de profissionais que pode ser representada pelo LinkedIn, por exemplo (LAUDON; LAUDON, 2007). As redes podem ser utilizadas para o compartilhamento da informação, favorecendo as relações entre si e o domínio das relações sociais através do engajamento (KHAN, 2015).

Nesse sentido, o engajamento dos estudantes nas instituições de ensino superior pode ser desenvolvido por meio de esferas que compõem a participação de estudantes vinculados ou, então, de usuários das MS que não estão vinculados com a instituição. Assim, deliberando elementos conteudísticos que sejam importantes e estratégicos para atrair um público externo em potencial e que possa vir a ingressar na instituição, ao mesmo tempo fortalecendo os vínculos dos estudantes já existentes (KHAN, 2015).

Choo (2003) qualifica que a estratégia é de extrema importância para a inovação dos processos de gestão, no que condiz a ser competente no uso da informação, de modo a obter conhecimento e prática significativa para determinado objetivo. Nesse contexto, a Gestão da Informação (GI) torna-se um 
fator extremamente importante para o desenvolvimento e customização de tempo e dinheiro nos ambientes profissionais e sociais (LAWSON et al., 2009).

A GI é um atributo elementar para a obtenção de resultados satisfatórios em uma organização (NONAKA; TAKEUCHI, 1997, VALENTIM, 2008). As MS, em especial, contribuem de maneira representativa para 0 compartilhamento da informação, disseminação da informação e a construção do conhecimento para o desenvolvimento estratégico (CURTIS, 2006). Desse modo, as instituições podem promover o engajamento de estudantes em potencial por meio do uso das MS e fazer uso da GI para a manutenção desse relacionamento, promovendo a otimização de recursos informacionais (PERREAULT; MOSCONI, 2018).

A proposta desta pesquisa é desenvolver um estudo sobre a inter-relação do conceito da GI e das MS, analisando os principais elementos abordados pelos autores e, por conseguinte, apresentar um panorama das práticas que as instituições de ensino superior podem adotar no manuseio das MS, ainda, pontuando as vantagens que as mídias podem oferecer por meio do engajamento dos estudantes através das plataformas digitais. Assim, é importante dizer, que, as instituições que buscam desenvolver o engajamento de estudantes nos perfis sociais midiáticos podem adquirir mais chances de receberem novos integrantes. Para tanto, a instituição escolhida para a realização do estudo de caso foi a Faculdade de Tecnologia (Fatec) Garça - localizada no interior do estado de São Paulo. A escolha foi instigada pela forte presença da instituição nas plataformas midiáticas e o envolvimento praticado com o público, atendendo os requisitos necessários na aplicabilidade do método desta pesquisa.

Diante do contexto apresentado, é importante dizer que poucos estudos mostram conteúdos e estratégias de interação social nas plataformas de MS. Além disso, as instituições de ensino superior mostram entendimento não evidente sobre técnicas de interação e engajamento por meio das mídias para o desenvolvimento de ações estratégicas e, inclusive, para a captação de estudantes nesse contexto.

As instituições podem apresentar dificuldade na captação de estudantes em alguns cursos oferecidos de diversas áreas. Considerando essa realidade, o 
que direcionou e instigou essa pesquisa foi a seguinte questão: quais as estratégias de conteúdo que contribuem para o engajamento dos atuais e futuros estudantes nas instituições de ensino superior por meio das MS? Sendo assim, esta pesquisa se justifica pelo fato de apresentar um estudo que acompanha as tendências atuais de comunicação em rede. Definiu-se como objetivo geral identificar as estratégias de conteúdo mais apropriadas para o uso das MS no engajamento dos estudantes. Para tanto, os objetivos específicos foram: investigar qual tipo de conteúdo existente nas mídias desperta mais atenção dos estudantes e do público e identificar os sinais de engajamento dos estudantes para a criação de estratégias de GI.

De modo geral, a contribuição desta pesquisa consiste em gerar indicadores para melhor identificação e aproveitamento das informações presentes nos perfis midiáticos das instituições de ensino superior. Além disso, oferecer um aporte na criação estratégica de conteúdo midiático para promover o engajamento dos estudantes atuais e em potenciais. Ainda, os resultados desta pesquisa oferecem dados que corroboram no preenchimento de lacunas e aprimoramento de ações.

\section{Metodologia}

Esta pesquisa caracteriza-se como exploratória e de natureza quantitativadescritiva, utilizando-se o método Estudo de Caso Yin (2010). Além disso, o presente estudo utilizou-se da pesquisa bibliográfica para identificar o conceito de Engajamento, GI e MS no contexto acadêmico. O universo da pesquisa envolve uma Instituição de Ensino Superior, brasileira, localizada na cidade de Garça, estado de São Paulo.

Os sujeitos da pesquisa envolvem 109 estudantes e dois funcionários da instituição. Os dois funcionários entrevistados são responsáveis pelas informações inseridas nos perfis das MS da instituição. No entanto, não possuem especialização em mídias, apenas são designados para promoverem a gestão das mídias por meio de cartilha disponibilizada pelo Centro Paula Souza, órgão responsável por manter a instituição de ensino. 
Os procedimentos metodológicos aqui traçados atuam na investigação dos fenômenos existentes no campo de estudo, por meio de técnicas e abordagens conceituais para identificação e construção de hipóteses através da realidade encontrada na instituição pesquisada. Deste modo, objetivando oferecer condições de contribuição social, acerca dos dados coletados e analisados.

Portanto, após a revisão bibliográfica, a pesquisa fundamenta-se pela aplicação do método Estudo de Caso, por meio da aplicação da técnica do questionário, entrevista e pesquisa documental, realizando a triangulação para a elaboração da análise dos resultados. Para a realização desta pesquisa aplicou-se o questionário com o apoio da ferramenta Google Docs aos estudantes. De acordo com Yin (2010), para análise e interpretação dos dados coletados é necessário realizar a triangulação, ou seja, analisar os resultados a partir de, no mínimo, três fontes de evidências.

A realização da revisão bibliográfica propiciou a construção do Quadro 1 contendo as principais abordagens conceituais sobre a GI e Fluxos Informacionais que corroboram para melhor aplicabilidade e utilização das MS, a partir da construção dos Indicadores (INOMATA; ARAÚJO; VARVAKIS, 2015; KHAN, 2015; PATEL, 2019; LORENTZEN, 2008; PHELPS; HEIDL; WADHWA, 2012).

Quadro 1 - Articulação entre o conceito de GI e diferentes abordagens conceituais de MS.

\begin{tabular}{|c|c|c|}
\hline $\begin{array}{l}\text { agens e } \\
\text { sões da GI }\end{array}$ & Mídias Sociais & $\begin{array}{l}\text { Indicadores para promover o } \\
\text { engajamento dos estudantes nas } \\
\text { instituições de ensino superior }\end{array}$ \\
\hline $\begin{array}{l}\text { Gerenciamento da } \\
\text { informação } \\
\text { Refere-se a gerenciar a } \\
\text { informação, reduzindo o } \\
\text { excesso, aperfeiçoar a } \\
\text { circulação, aperfeiçoar o } \\
\text { fluxo da informação, } \\
\text { identificar com precisão } \\
\text { as informações } \\
\text { necessárias e descartar as } \\
\text { inúteis ou redundantes. } \\
\text { Procedimentos da GI } \\
\text { Conjunto de ações que } \\
\text { visa à identificação de } \\
\text { necessidades, o } \\
\text { mapeamento de fluxos }\end{array}$ & $\begin{array}{l}\text { Tecnologia midiática } \\
\text { As redes sociais digitais, } \\
\text { ou originalmente redes } \\
\text { sociais, consistem em } \\
\text { ferramentas } \\
\text { informacionais que podem } \\
\text { constituir relacionamentos, } \\
\text { sejam afetivos ou } \\
\text { profissionais, bem como o } \\
\text { compartilhamento de } \\
\text { interesses e objetivos } \\
\text { comuns por meio da } \\
\text { internet. } \\
\text { Tecnologia } \\
\text { comunicacional } \\
\text { Um novo sistema de }\end{array}$ & $\begin{array}{l}\text { As MS são ferramentas tecnológicas } \\
\text { da informação que disponibilizam } \\
\text { campos digitais para inserção de } \\
\text { informações para internautas e } \\
\text { usuários. } \\
\text { As instituições de ensino superior } \\
\text { podem estabelecer contato com o } \\
\text { público disponibilizando no perfil } \\
\text { social informações sobre produtos e } \\
\text { serviços, identificando o melhor } \\
\text { horário para publicação. } \\
\checkmark \text { Designar um profissional } \\
\text { responsável para manusear e } \\
\text { organizar as informações } \\
\text { inseridas e captadas do perfil } \\
\text { social da instituição. }\end{array}$ \\
\hline
\end{tabular}




\begin{tabular}{|c|c|c|}
\hline $\begin{array}{lr}\text { apoiar } & \text { o } \\
\text { ento } & \text { das } \\
\text { otidianas } & \text { e a }\end{array}$ & 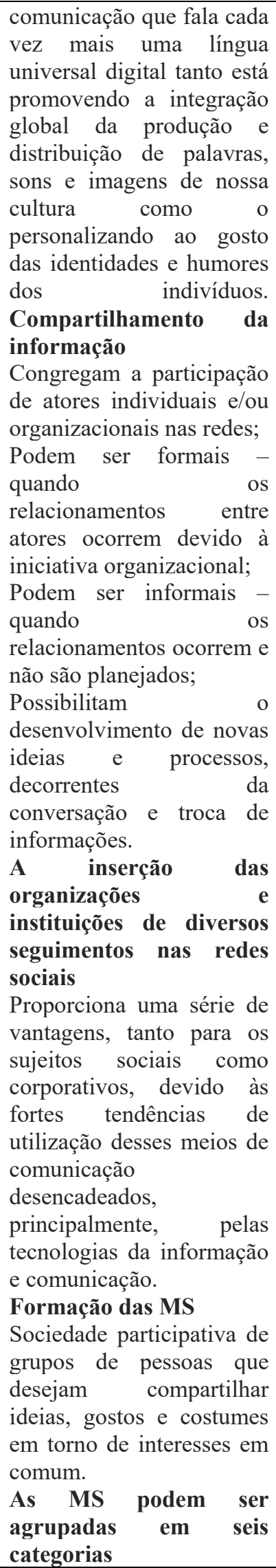 & 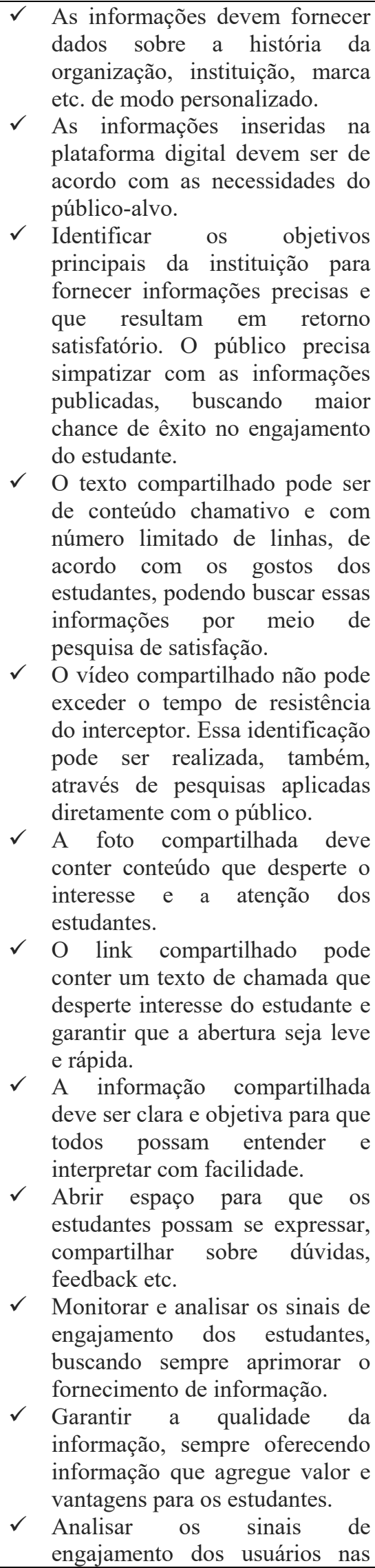 \\
\hline
\end{tabular}




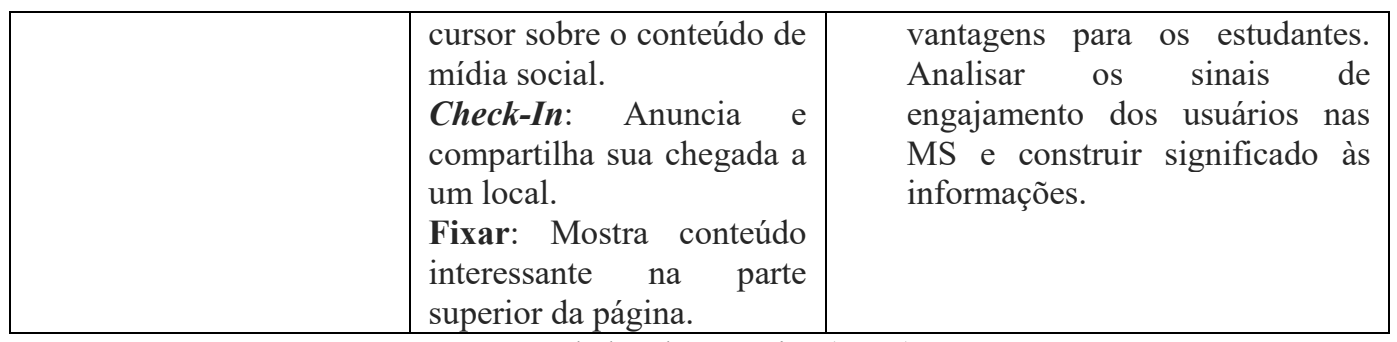

Fonte: dados da pesquisa (2021).

\section{Resultados e discussões}

Como resultado da pesquisa documental, primeiramente, apresentam-se os dados captados da interação social entre a instituição e os estudantes por meio do perfil oficial, no Facebook, da Faculdade de Tecnologia de Garça, conforme mostra a Tabela 1 a seguir. Foi escolhido o Facebook como objeto de análise e estudo por se tratar da mídia social mais utilizada no Brasil e, também, em virtude de ser a rede social que mais pode promover o engajamento de estudante em potencial nas instituições de ensino (SARDELARI, 2017; PATEL, 2019).

Tabela 1 - Análise de conteúdo da página Facebook da Fatec Garça

\begin{tabular}{|c|c|c|c|c|c|c|c|c|c|c|}
\hline \multicolumn{11}{|c|}{15 outubro 2019 a 13 novembro 2019} \\
\hline $\begin{array}{c}4932 \\
\text { Usuários }\end{array}$ & $\begin{array}{c}\text { Número } \\
\text { publicacóes } \\
\%\end{array}$ & $\begin{array}{c}\text { Soma do } \\
\text { número } \\
\text { curtidas }\end{array}$ & $\begin{array}{c}\% \text { de } \\
\text { curtidas } \\
\text { de total } \\
\text { desse tipo }\end{array}$ & $\begin{array}{c}\text { Número } \\
\text { médio } \\
\text { de } \\
\text { curtidas } \\
\text { desse } \\
\text { tipo }\end{array}$ & $\begin{array}{l}\text { Soma do } \\
\text { número de } \\
\text { comentários }\end{array}$ & $\begin{array}{l}\% \text { de } \\
\text { comentírios } \\
\text { do total desse } \\
\text { tipo }\end{array}$ & $\begin{array}{c}\text { Número } \\
\text { médio de } \\
\text { comentários } \\
\text { desse tipo }\end{array}$ & $\begin{array}{c}\text { Soma do número } \\
\text { de } \\
\text { compartilhamentos }\end{array}$ & $\begin{array}{c}\% \text { de } \\
\text { compartilhamentos } \\
\text { do total desse tipo }\end{array}$ & $\begin{array}{l}\text { Número médio de } \\
\text { compartilhamentos } \\
\text { desse tipo }\end{array}$ \\
\hline Link & $\begin{array}{c}19 \\
7,7 \%\end{array}$ & 109 & $1,8 \%$ & 5,74 & 10 & $2,6 \%$ & 0,53 & 53 & $7,8 \%$ & 5,3 \\
\hline Foto & $\begin{array}{c}200 \\
81,30 \%\end{array}$ & 5.766 & $94,6 \%$ & 28,8 & 362 & $92,3 \%$ & 1,81 & 565 & $83,3 \%$ & 3,28 \\
\hline Video & $\begin{array}{c}27 \\
11 \%\end{array}$ & 218 & $3,6 \%$ & 8 & 20 & $5,1 \%$ & 0,74 & 60 & $8,9 \%$ & 2,22 \\
\hline Total geral & 246 & 6.093 & $100 \%$ & & 392 & $100 \%$ & & 678 & $100 \%$ & \\
\hline
\end{tabular}

Fonte: dados da pesquisa (2019).

Os dados apresentados no Tabela 1 são correspondentes aos sinais de engajamento dos estudantes por meio das métricas que a ferramenta digital disponibiliza na plataforma. Todo o conteúdo que abrange o período estudado está relacionado ao vestibular, prazo de inscrição, data, horário da prova e lembretes, como também, promoção aos atuais estudantes, ex-estudantes e 
conteúdo institucional. Assim, destaca-se em vermelho os números que correspondem ao menor índice de engajamento em relação à categoria do tipo de conteúdo e em azul o maior índice.

De acordo com a Tabela 1, a estratégia mais utilizada pela Fatec Garça é a publicação de fotos. Essa estratégia representa um percentual de $81,30 \%$ de todas as publicações do período analisado, seguido de $11 \%$ de vídeos e 7,7\% de links, de um total de 246 publicações. Observa-se que os estudantes curtem mais as fotos, com uma média de 28,8 de curtidas comparado ao link e vídeo, com média de 8 e 5,74, respectivamente. O número de curtidas representa 5.766, seguido de 218 para vídeos e 109 para os links.

Percebe-se que o nível de engajamento pode ser relativo, pois é possível perceber que, ao curtir uma foto ou vídeo, o mesmo usuário não necessariamente pode ter se interessado pelas demais publicações. Sendo assim, é importante ressaltar que a ideia de promover o engajamento dos estudantes é desenvolver a confiança dos usuários visando oferecer informações que atendam a um público diversificado e que esteja inserido no ambiente midiático.

Logo, em seguida, constatou-se que as curtidas nas fotos foram as métricas identificadas que mais colaboraram com o aumento do engajamento dos estudantes. Assim, foi possível obter uma média de 1,81 de comentários, comparado ao link e vídeo, com média de 0,53 e 0,74 , respectivamente. O número de comentários para as fotos se destaca, representando 362 comentários, seguido de 20 para vídeos e dez para os links. Nesse contexto, percebe-se que a interação ocorre mais com as publicações de fotos. Pode-se entender que as fotos são publicações de fácil leitura e interpretação. Assim, compreender a necessidade de investimento em publicações de fotos com imagens dinâmicas podem despertar mais o interesse e favorecer, inclusive, no aumento de compartilhamentos. Desta forma, o alcance das publicações pode ir mais além e atrair novos membros para a página social da instituição, consequentemente, podendo despertar o interesse dos usuários e atrair novos estudantes para a Fatec.

É possível identificar dados interessantes para o número de compartilhamento em relação às categorias do conteúdo. Os estudantes 
compartilham mais conteúdo de links, posicionando as fotos em segunda colocação no número médio de compartilhamento e em terceiro os vídeos. A média de compartilhamento para links é de 5,3, sendo de 2,22 para vídeos e 3,28 para fotos. Os números de compartilhamento são de 565 para fotos que se destacam, comparados a 60 para vídeos e 53 para links. O link não é a estratégia de melhor desempenho em termos de envolvimento total, mas permite obter muito mais compartilhamentos, representando a maior média para a categoria dos tipos de conteúdo analisados. Nota-se a importância de observar e promover imagens e textos mais chamativos para atrair a atenção dos usuários, estimulando mais compartilhamentos. O compartilhamento de conteúdo institucional a partir dos estudantes é uma ação elementar para aumentar o engajamento dos atuais e futuros estudantes.

\section{A próxima técnica de coleta de dados corrobora a pesquisa}

\section{documental por meio da análise dos dados coletados pelo questionário.}

A primeira questão abordou o direito de escolha dos estudantes participantes em conceder a autorização da divulgação dos dados coletados. Em seguida, a identificação do gênero: feminino 50,5\% e masculino 49,5\%. Não houve, por parte dos estudantes, manifestações de outros tipos de gêneros. Quanto à faixa etária, 66,1\% dos estudantes pesquisados possuem entre 18 e 25 anos de idade, seguido de 29,4\% estudantes entre 26 e 40 anos, 3,7\% entre 41 e 55 anos e $0,9 \%$ entre 56 e 75 anos de idade. O grau profissional dos estudantes destaca a graduação em andamento, representado por $67,9 \%$ de todos os 109 participantes, $16,5 \%$ de estudantes já possuem graduação concluída, 12,8\% especialização, $0,9 \%$ mestrado, $0,9 \%$ doutorado e $0,9 \%$ possui pós-doutorado.

Nesse contexto, é importante dizer que há uma diversidade de perfis que acessam e utilizam as MS da instituição. De tal modo, há uma distribuição uniforme da informação nos perfis sociais, considerando diferentes faixas etárias, gêneros e cursos. Portanto, no âmbito das MS, nota-se uma democratização da informação, ou seja, um maior nível de acessibilidade da informação por todos os tipos de público. 


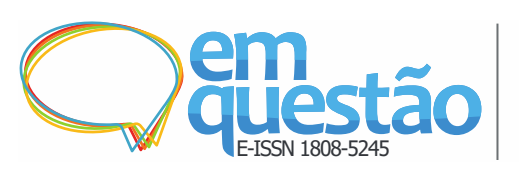

Gestão da informação e mídias sociais para o engajamento dos estudantes nas instituições de ensino superior

Everaldo Henrique dos Santos Barbosa, Cássia Regina Bassan de Moraes

Figura 1 - Horário de acesso.

5 - Qual horário você passa mais tempo acessando às mídias sociais?

109 respostas

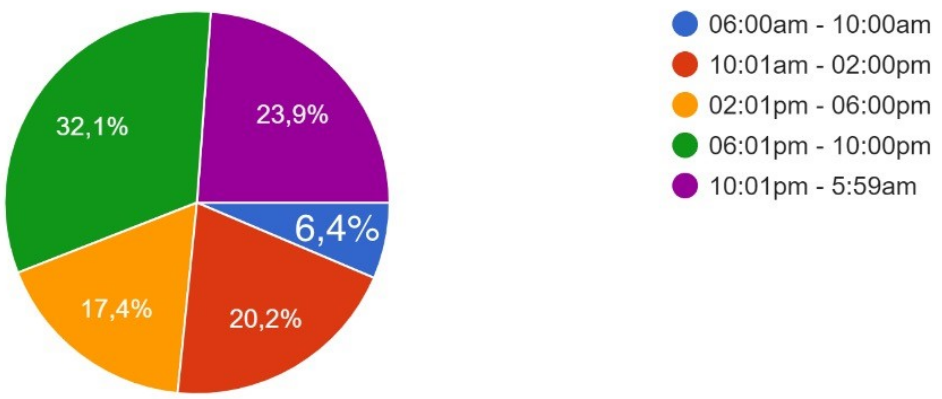

Fonte: dados da pesquisa (2019).

A Figura 1 mostra os horários que os internautas mais acessam as MS. As opções foram agrupadas de quatro em quatro horas e divididas em cinco períodos do dia e da noite. Assim, foi possível identificar que o maior pico de acesso se encontra das $06: 01 \mathrm{pm}$ às $10 \mathrm{pm}$, representando $32,1 \%$, seguido de $23,9 \%$ entre $10: 01 \mathrm{pm}$ às $5: 59 \mathrm{am}, 20,2 \%$ entre $10: 01 \mathrm{am}$ às $02: 00 \mathrm{pm}, 17,4 \%$ entre 02:01pm às 06:00pm e, na última posição, 6,4\% entre 06:00am às 10:00am, destacado em azul.

De acordo com os resultados para as publicações compartilhadas aos usuários das MS, é mais indicado ser realizado durante os horários de pico, pois irá proporcionar maior índice de visualização e notoriedade por parte dos usuários. O horário de pico, identificado das $06: 00 \mathrm{pm}$ às $10 \mathrm{pm}$, está relacionado com o tempo em que os usuários passam mais tempo nas MS, logo, concentrar as publicações no início deste período aumentam as chances de engajamento, trazendo mais vantagem para a instituição.

Nesse sentido, foi questionado qual o site ou aplicativo de MS mais acessado pelos estudantes. Assim, foi possível obter os seguintes dados com relação a questão apresentada. Das 109 respostas 38,5\% responderam que acessam mais o Facebook, seguido de 28,4\% pelo WhatsApp e 18,3\% Instagram. As três primeiras colocadas são as que mais se destacam no mundo das MS e, também, são os sites de rede sociais que a instituição mais se interage com relação aos usuários, permitindo um entrosamento mais direto, rápido e 
eficaz. Outras MS que se destacaram foram o YouTube com 7,3\% e LinkedIn com $1 \%$. Dentre os entrevistados, houve um percentual de estudantes que não soube responder qual MS que mais utilizam, sendo 7,5\% do total de 109 . De acordo com essas informações é possível identificar as MS que mais atraem a atenção dos estudantes, possibilitando o desenvolvimento de estratégias para reforçar o envolvimento entre instituições, atuais e futuros estudantes. A divulgação de informação relevante nessas plataformas agrega valor e aumenta a possibilidade de atingir um público específico em nível mais amplo.

Portanto, indica-se aumentar ou promover maior fluxo de publicação no Instagram, visto que o foco da instituição estudada é publicar e manter um fluxo contínuo de conteúdo no Facebook. Considerando que o Instagram é uma mídia social de alto potencial e tendo em vista que o WhatsApp, segunda rede social mais utilizada, é uma ferramenta midiática mais fechada e limitada.

Desta forma, possuir envolvimento contínuo com o público em várias plataformas midiáticas propicia maior envolvimento e mais aproximação com o público, visto que as tendências mudam e novos sites de redes sociais surgem.

Figura 2 - Preferência do tipo de conteúdo.

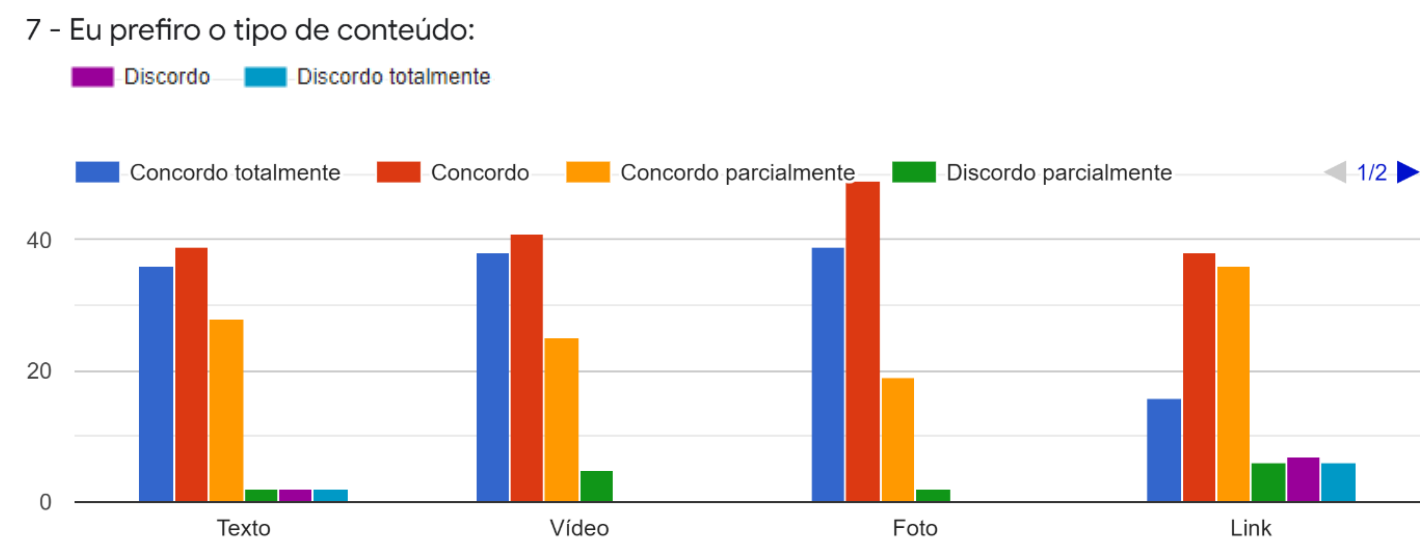

Fonte: dados da pesquisa (2019).

A Figura 2 trouxe a abordagem da preferência dos estudantes quanto ao tipo de conteúdo publicado pela instituição e as opções foram sobre publicações de conteúdo de texto, vídeo, foto e link. A informação compartilhada deve ser clara e de interesse do interceptor, o envolvimento dos interceptores se perfaz 
por sinais de engajamento mediante as funcionalidades das MS. O estudante quando visualiza uma publicação pode interagir expondo suas emoções, como reagindo ao conteúdo por meio de um like (gostar) na publicação e, também, é possível compartilhar ou comentar o conteúdo (KHAN, 2015).

Para melhor demonstração dos dados sobre a preferência do tipo de conteúdo dos estudantes, apresenta-se o Quadro 2 a seguir.

Quadro 2 - Preferência do tipo de conteúdo dos estudantes.

\begin{tabular}{|c|c|c|c|c|}
\hline $\begin{array}{c}109 \\
\text { Estudantes }\end{array}$ & Texto & Vídeo & Foto & Link \\
\hline $\begin{array}{c}\text { Concordo } \\
\text { totalmente }\end{array}$ & 36 & 38 & 39 & 16 \\
\hline $\begin{array}{c}\text { Concordo } \\
\text { Concordo } \\
\text { parcialmente }\end{array}$ & 39 & 41 & 49 & 38 \\
\hline $\begin{array}{c}\text { Discordo } \\
\text { parcialmente }\end{array}$ & 28 & 5 & 2 & 36 \\
\hline Discordo & 2 & 0 & 0 & 6 \\
\hline $\begin{array}{c}\text { Discordo } \\
\text { totalmente }\end{array}$ & 2 & 0 & 0 & 6 \\
\hline
\end{tabular}

Fonte: dados da pesquisa (2019).

No Quadro 2, identificou-se que os tipos de conteúdo que os estudantes preferem são os seguintes: fotos em primeiro lugar, em segundo vídeo e em terceiro o texto, considerando que em todo tipo de publicação há texto. Portanto, é evidente que oferecer mais atenção em publicações de fotos e vídeos pode atrair mais a atenção dos estudantes. Sendo assim, atender às preferências dos usuários melhora os níveis de engajamento e proporciona mais satisfação aos usuários, estimulando o compartilhamento com outros amigos virtuais que possuem a mesma mídia social. 
Figura 3 - Conteúdo mais útil para os estudantes.

8 - O tipo de conteúdo mais útil é:

Discordo Discordo totalmente

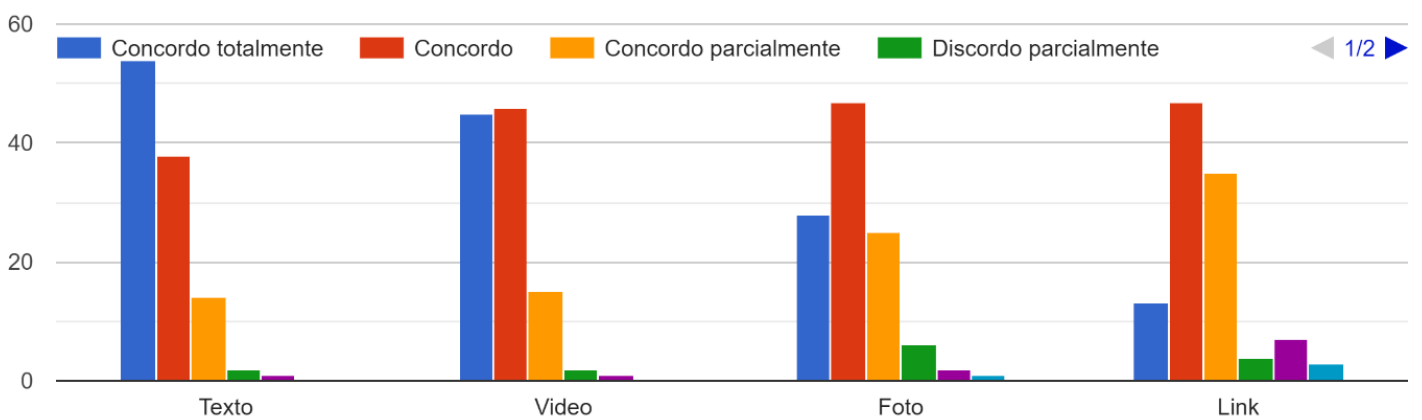

Fonte: dados da pesquisa (2019).

Estar ciente de gerenciar as informações publicadas é de extremo valor para garantir a satisfação do público. Portanto, a Figura 3 trouxe a tratativa relacionada tanto à satisfação quanto a utilidade do tipo de conteúdo publicado pela instituição.

Assim, as opções foram sobre publicações de conteúdo de texto, vídeo, foto e link. Portanto, neste mesmo sentido, para melhor demonstração dos dados sobre o conteúdo mais útil para os estudantes, apresenta-se a seguir o Quadro 3.

Quadro 3 - Conteúdo mais útil para os estudantes.

\begin{tabular}{|c|c|c|c|c|}
\hline 109 Estudantes & Texto & Vídeo & Foto & Link \\
\hline $\begin{array}{c}\text { Concordo } \\
\text { totalmente }\end{array}$ & 54 & 45 & 28 & 13 \\
\hline Concordo & 38 & 46 & 47 & 47 \\
\hline $\begin{array}{c}\text { Concordo } \\
\text { parcialmente }\end{array}$ & 14 & 15 & 25 & 35 \\
\hline $\begin{array}{c}\text { Discordo } \\
\text { parcialmente }\end{array}$ & 2 & 2 & 6 & 4 \\
\hline Discordo & 1 & 1 & 2 & 3 \\
\hline $\begin{array}{c}\text { Discordo } \\
\text { totalmente }\end{array}$ & 0 & 0 & 1 & 7 \\
\hline
\end{tabular}

Fonte: dados da pesquisa (2019).

Face ao exposto no Quadro 3, é possível identificar que o tipo de conteúdo que os estudantes classificam como mais útil é o texto, estando em primeiro lugar. Em segundo o vídeo e em terceiro as fotos. Desenvolver estratégias de conteúdo em formato de texto inserido em vídeos torna-se uma 
forma de instigar o engajamento dos usuários na plataforma, visto que nas fotos a instituição já insere textos.

Ressalta-se que a satisfação do usuário faz com que as possibilidades de compartilhamento aumentem, ou seja, o conteúdo publicado nas plataformas sociais digitais da instituição deve ser do interesse dos estudantes. Desta maneira, esta ação proporciona maior engajamento por parte dos estudantes internos e àqueles em potencial. Assim, a informação deve ser clara e objetiva para atender às necessidades dos interceptores, de maneira que faça sentido para o leitor.

Figura 4 - Frequência de uso das MS.

9 - Qual sua frequência de uso das mídias sociais?

109 respostas

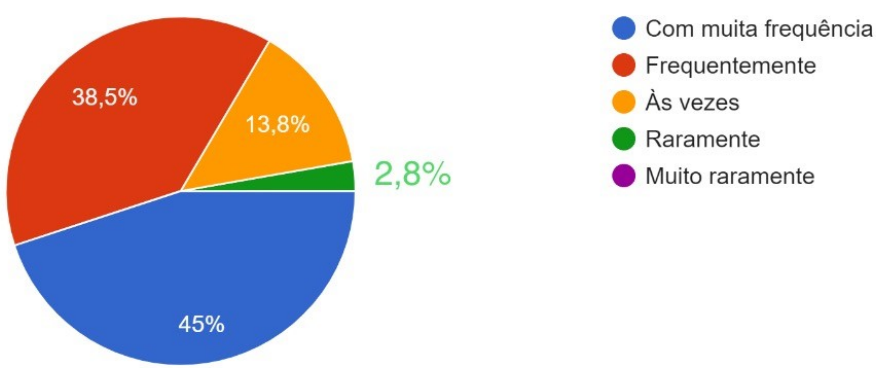

Fonte: dados da pesquisa (2019).

A sociedade está cada vez mais acessando as redes sociais digitais. Com isso, identificar alguns fatores como os horários e a frequência de uso das mídias pode favorecer no desenvolvimento de estratégias de conteúdo. Assim, na Figura 4 foi possível identificar qual a frequência de uso das MS pelos estudantes da instituição pesquisada. Os dados mostram que 45\% dos participantes acessam a plataforma com muita frequência, 38,5\% frequentemente, $13,8 \%$ às vezes e $2,8 \%$ raramente. Ou seja, identificar o horário de maior pico de acesso é fundamental para atingir o público no momento em que ele está conectado. 


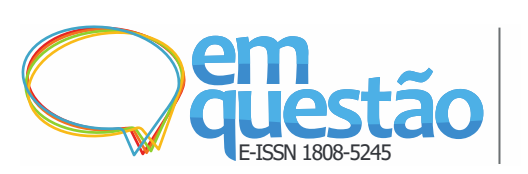

Gestão da informação e mídias sociais para o engajamento

dos estudantes nas instituições de ensino superior

Everaldo Henrique dos Santos Barbosa, Cássia Regina Bassan de Moraes

Figura 5 - Frequência de curtidas.

10 - Com qual frequência você curte as publicações?

109 respostas

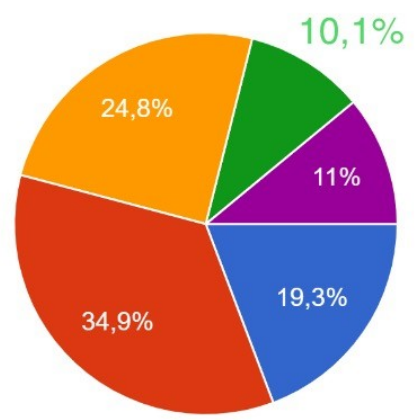

Com muita frequência

Frequentemente

Às vezes

Raramente

Muito raramente

Fonte: dados da pesquisa.

Na Figura 5 foi abordada uma questão para identificar a frequência que os estudantes curtem as publicações. Os dados apresentam que 34,9\% dos estudantes curtem as publicações frequentemente, $24,8 \%$ às vezes, $19,3 \%$ com muita frequência, $11 \%$ muito raramente e 10,1\% raramente. Portanto, há uma incidência considerável, a partir das junções das respostas dos estudantes. Notase que ao curtir uma publicação o usuário está reagindo e expondo sua satisfação ao conteúdo que representa a instituição, fortalecendo seus vínculos e estimulando o engajamento de outros usuários.

A identificação dessas informações mostra que grande parte dos entrevistados curte frequentemente as publicações, sendo um sinal positivo de envolvimento em relação aos usuários e o conteúdo publicado. Estar atento aos sinais de engajamento pode direcionar os gestores da instituição a desenvolver maneiras eficazes de compartilhar informação e conteúdo de qualidade para que os usuários mantenham um envolvimento mais fluente na plataforma.

Portanto, identificar a frequência de curtidas é uma maneira de acompanhar se os usuários estão gostando ou não do conteúdo que está sendo disponibilizado, então, torna-se um fator que permite aprimorar e desenvolver estratégias de conteúdo por meio da gestão das informações produzidas. 
Figura 6 - Preferência de compartilhamento de conteúdo específico.

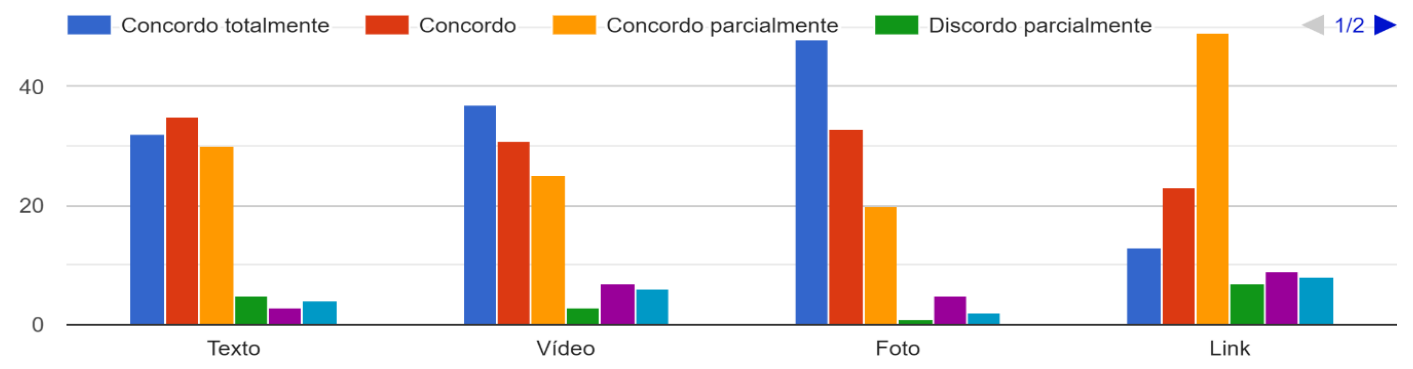

Fonte: dados da pesquisa (2019).

O fluxo da informação, por meio do compartilhamento, é um fator fundamental para a disseminação da informação. A qualidade da informação é um fator essencial para que o conteúdo seja reconhecido e valorizado no âmbito das MS. Na Figura 6 foi questionado se os estudantes preferem compartilhar conteúdo de formato texto, vídeo, foto ou link. Assim, dos 109 participantes, o tipo de conteúdo texto apresentou que 32 concordam plenamente, 35 concordam, 30 concordam parcialmente, cinco discordam parcialmente, três discordam e quatro discordam totalmente. A preferência em compartilhar conteúdo de vídeo mostrou que 37 concordam totalmente, 31 concordam, 25 concordam parcialmente, três discordam parcialmente, sete discordam e seis discordam totalmente. A foto teve como resultado um total de 48 para concordo totalmente, 33 concordo, 20 concordo parcialmente, um discordou parcialmente, cinco discorda e dois discorda totalmente.

O link obteve um total de 13 concordo totalmente, 23 concordo, 49 concordo parcialmente, sete discordo parcialmente, nove discordo e oito discordo totalmente. Os resultados mostraram que o tipo de conteúdo que os estudantes preferem compartilhar mais é do tipo foto, seguido de vídeo. Um índice considerável mostrou que 49 participantes concordam parcialmente com compartilhamento do tipo link. Comparando com os demais tipos de conteúdo foi o que mais se destacou depois de foto. O texto teve uma representação mediana por conter votos do mesmo nível para todas as opções de preferências. 
Considerando o tipo de conteúdo de foto e link como de maior destaque, é possível a instituição desenvolver conteúdo estratégico para este tipo de publicação. É muito importante para a instituição quando um estudante atual compartilha um conteúdo. O envolvimento de novos usuários é mais propício quando um atual estudante divulga informações da própria instituição o qual está vinculado.

Figura 7 - Preferência da quantidade de linhas dos textos.

12 - Eu prefiro quando os textos publicados possuem:

109 respostas

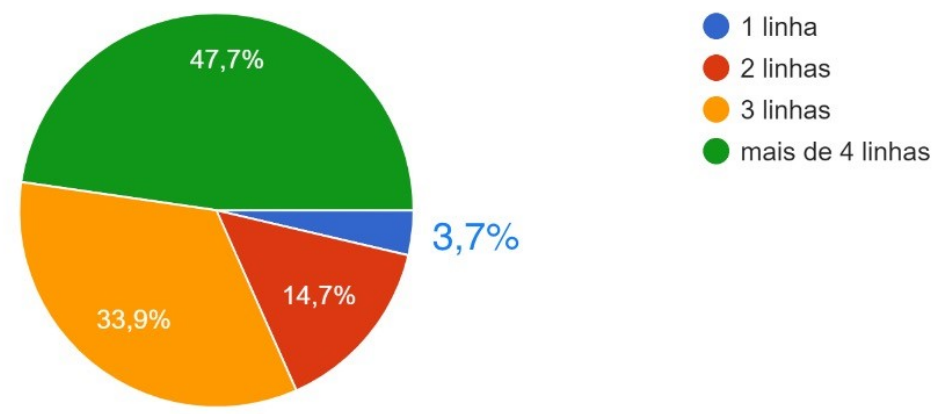

Fonte: dados da pesquisa (2019).

A Figura 7 aborda a questão das preferências dos estudantes da instituição pesquisada quanto à quantidade de linhas dos textos publicados. Essa identificação, segundo Khan (2015), possibilita melhorar o nível de engajamento dos usuários. Portanto, ao identificar essas informações é possível desenvolver conteúdo adequado às exigências dos interceptores. Identificou-se que 47,7\% preferem textos com mais de quatro linhas, 33,9\% textos com três linhas, 14,7\% textos com duas linhas e 3,7\% preferem textos de uma linha. Os dados apresentados expõem a preferência dos usuários em potencial e, assim, atender a esses aspectos é importante para que a informação seja mais absorvida pelos receptores. Um texto com poucas linhas ou com uma quantidade exacerbada faz o leitor perder o interesse pelo conteúdo ou não o absorver de maneira considerável. Sendo assim, é relevante ter consciência da quantidade de linhas apropriadas para o leitor em potencial. Nesse sentido, expõe-se que a publicação com textos inseridos nos links ou fotos devem conter mais de quatro linhas, 
considerando que menos do que isso pode não chamar a atenção e, também, não conter uma informação mais clara e suficiente para aquele que está realizando a leitura.

Figura 8 - Preferência da duração do vídeo publicado.
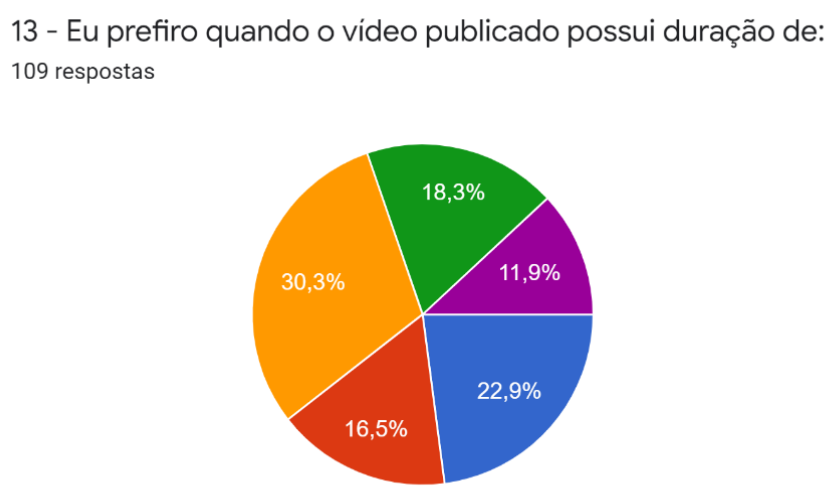

1 - 15 segundos

Fonte: dados da pesquisa (2019).

O tipo de conteúdo de vídeo desperta o interesse de boa parte dos usuários das MS, no entanto, identificar a duração do vídeo que mais agrada o interceptor é um fator importante para atrair e manter a atenção das pessoas. Portanto, foi questionado qual a preferências dos estudantes quanto à duração dos vídeos publicados. Assim, os dados coletados mostram que 30,3\% preferem vídeos de duração entre 31 e 60 segundos, 22,9\% preferem vídeos de duração entre 1 e 15 segundos, 18,3\% duração entre 61 e 90 segundos, 16,5\% preferem duração entre 16 e 30 segundos e 11,9\% preferem vídeos de duração com mais de 90 segundos. Sendo assim, enfatiza-se que os vídeos oferecem a possibilidade de inserção de conteúdo mais dinâmico e que chama mais a atenção dos estudantes em potencial, deliberando oportunidades significativas para a instituição explorar.

De acordo com esses dados, há evidências que comprovam as preferências dos usuários das MS por vídeos curtos, ou seja, com duração de menos de um minuto. Portanto, recomenda-se que os vídeos sejam criados com informação muito direta e objetiva para poder sanar todas as necessidades informacionais dos estudantes em curto tempo e ao mesmo tempo. 
A seguir, apresentam-se, em síntese, as entrevistas realizadas com os responsáveis pela gestão das MS da Fatec Garça.

Esta etapa refere-se à análise das respostas obtidas com o uso da técnica de entrevista estruturada, seguindo o roteiro de questões pré-determinadas.

Foram entrevistados dois funcionários - Entrevistada A: sexo feminino, diretora de serviço, idade 31 anos, tempo de trabalho 11 anos, promove a gestão das informações inseridas nas MS, oferecendo informações que são úteis para os estudantes ou público interessado. Entrevistado B: sexo masculino, auxiliar docente, idade 27 anos, tempo de trabalho seis anos, realiza o manuseio de conteúdo nas MS e interage com os estudantes e usuários.

As atribuições dos funcionários responsáveis pela gestão das MS demonstram estabelecer um relacionamento direto com o público das MS da instituição. O contato frequente com a informação é evidente e exige da profissional habilidade para a realização de tarefas eficazes.

Nesse sentido, os funcionários da instituição devem aplicam a GI a fim de adquirir, armazenar e disseminar, de maneira estratégica, informações exatas e pontuais que propiciem tomadas de decisões mais assertivas.

Primeiramente, é importante destacar a consciência dos entrevistados em promover uma eficiente GI para que os resultados sejam mais consistentes e de qualidade. Essa afirmação corrobora os conceitos esboçados na Articulação entre o conceito de GI e diferentes abordagens conceituais de MS, construídos nesta pesquisa.

O Centro Paula Souza, mantenedor da instituição pesquisada, disponibiliza um manual de orientações para a disseminação de informações nas MS. Tais orientações são seguidas para padronização das informações entre as unidades de ensino e assegurando que informações incorretas não sejam disponibilizadas.

Os entrevistados declararam que o engajamento em MS é extremamente importante, com o passar do tempo e a modernização dos meios sociais de comunicação e divulgação de informações, perceberam que a transmissão de informações, através do uso da internet, elimina fronteiras terrestres e alcançam um público maior, utilizando menos tempo e recursos financeiros do que outros 
meios. Por conseguinte, o engajamento do público junto à instituição por meio das MS potencializa a divulgação das informações de forma exponencial. Somente a interação de uma pessoa já é capaz de divulgar um conteúdo para diversos amigos em comum. Além disso, para atingir o público alvo da melhor forma possível deve-se sempre buscar modernizar os mecanismos de interação, estando sempre atualizado e seguindo com as tendências de comunicação que a sociedade mais utiliza em determinado período histórico.

Os tipos de MS utilizados pela instituição são Facebook, Instagram e WhatsApp. Também, foi explicado que o Instagram e o WhatsApp são ferramentas pouco utilizadas. Essas MS, mencionadas pelo auxiliar de docente, estão classificadas entre as cinco mais utilizadas pelos brasileiros nos anos de 2018 e 2019, segundo Patel (2019). No entanto, a instituição possui um fluxo maior de utilização no Facebook. O engajamento em MS pode resultar em resultados positivos para as instituições pesquisadas e todas as outras que se dedicam a utilizar e disponibilizar informação de qualidade para o público. Ainda, o público-alvo ao utilizar as MS são alunos atuais da instituição, egressos, futuros estudantes e candidatos ao vestibular.

É importante dizer que a GI, proveniente das MS, pode favorecer no desenvolvimento de ideias e estratégias por um determinado objetivo. De acordo com a resposta do entrevistado, nota-se que o contato com atuais e futuros estudantes acarreta em maior envolvimento com a sociedade e que utilizar os rastros deixados pelos usuários nas plataformas sociais é um caminho importante para grandes conquistas junto à instituição.

As páginas do Facebook e Instagram são utilizadas pela instituição para divulgação de informações de interesse geral dos estudantes, como prazos, datas e eventos que foram realizados. O Messenger do Facebook e o WhatsApp são ferramentas para sanar dúvidas individuais dos alunos.

São compartilhados textos curtos e imagens, de forma mais sucinta e objetiva possível, visando maior alcance e tentando não desprender o interesse da comunidade na leitura das informações. Os objetivos institucionais se destacam por instigar, através das MS, a atração pela Fatec, referindo-se em publicações que despertem o interesse do público em interagir com a instituição. 
Essa interação proporciona o engajamento no qual está relacionado com ações individuais de acompanhamento, interesse e inserção dos interceptores, no que a unidade oferece e disponibiliza para a sociedade. A instituição reconhece que a memória da Fatec é preservada. Nesse quesito, o funcionário retrata as ações tomadas quanto às informações que são tratadas nos compartilhamentos, pois cada evento, ação institucional ou projeto desenvolvido são publicados e armazenados para preservar os acontecimentos.

Ainda, as entrevistas evidenciaram que os objetivos da instituição, com relação ao uso das MS (Facebook, Instagram, entre outros), são promover a divulgação da instituição e levar informação ao público e aos discentes.

\section{A próxima etapa consistiu na triangulação.}

Nesta etapa da pesquisa, relacionaram-se os dados coletados diretamente das MS com as respostas concedidas pelos participantes do questionário, representados pelos estudantes da instituição de ensino, juntamente com as respostas concedidas pela aplicação da entrevista estruturada realizada com os responsáveis pelas MS. Em síntese, a triangulação indicou os seguintes resultados:

a) $\mathrm{O}$ auxiliar docente e a diretora de serviço da instituição pesquisada possuem consciência da importância da valorização da informação e da GI no apoio aos objetivos que visem ao engajamento dos atuais e futuros estudantes por meio das MS.

b) Os responsáveis pelas MS praticam atos dinâmicos para garantir o envolvimento e engajamento dos estudantes e garantem que essa prática é importante para o desenvolvimento estratégico na captação de estudantes.

c) A instituição utiliza várias plataformas de MS para se comunicar com o público-alvo e estabelece uma linha comunicacional para atender os interessados com maior frequência no Facebook, porém, não possuem profissionais especialistas em MS. Os funcionários são instruídos pelo Centro Paula Souza, órgão que administra as faculdades instaladas no estado de São Paulo. 
d) Toda a informação que a instituição obtém, por meio das MS, é armazenada para futuro acesso, desenvolvimento de estratégias e tomadas de decisão.

e) O principal foco da instituição nas MS é a captação de estudantes e a manutenção do envolvimento com os atuais. Os resultados têm sido promissores, no entanto, esse panorama pode sempre ser aprimorado por meio de estratégias de conteúdo.

f) O perfil da instituição no Facebook possui 4.932 usuários e 246 publicações para um intervalo de um mês. Nota-se que o envolvimento com o público é bastante frequente e que, talvez, isso deva ser tratado com mais atenção para não saturar a imagem da instituição, de acordo com a frequência e o conteúdo publicado. Retratando o número de publicações em 246 para o período pesquisado, não se enquadra para os demais períodos, pois foi abordado apenas o período do vestibular pelo qual é intensificado o fluxo de publicações.

g) Os sinais de engajamento são bastante evidentes na plataforma digital social da instituição. Com as métricas observadas, identificou-se que há uma divisão de maior atenção aos links e fotos compartilhados. Esta observação remete a uma atenção maior aos gostos e interesses dos estudantes, podendo ser identificada por meio de pesquisa aplicada diretamente a eles.

h) Dos atuais estudantes pesquisados, $82,6 \%$ afirmaram que se sentem mais próximos da instituição. Essa informação denota a importância do envolvimento entre a instituição e os estudantes para fortalecer os vínculos, gerando mais confiabilidade entre as partes e a propagação de um ambiente confortável.

i) Os estudantes puderam expressar seus gostos ao afirmarem a quantidade de linhas dos textos publicados e o tempo dos vídeos que mais os agradam. Essas informações permitem que o controle do conteúdo seja realizado a partir das informações geradas pelos próprios interceptores do perfil social. Desta forma, identificar os principais pontos que podem desenvolver o engajamento do público com a instituição, torna-se um 
fator plausível diante das possibilidades existentes por meio dessas informações captadas.

\section{Considerações finais}

A partir dos pressupostos abordados, realizou-se uma investigação paralela com a realidade da instituição estudada. Constatou-se que a instituição possui, principalmente, um sistema de utilização das MS voltado a informação interna, divulgação de vestibulares e captação de estudantes. Assim, a recomendação é que a instituição pesquisada invista na implantação de sistemas midiáticos que sejam gerenciados por profissionais especializados e capacitados, considerando vários cursos profissionalizantes que o mercado oferece e, inclusive, utilizando parâmetros dos resultados gerados pela presente pesquisa.

A Fatec Garça, por meio das entrevistas, evidencia obter retorno das publicações voltadas à captação de estudantes por meio das MS, porém, são dados não explícitos. Com isso, é recomendável uma atenção maior ao conteúdo publicado para que seja oferecida uma informação mais diretiva e, ao mesmo tempo, em formato de entretenimento. As MS são plataformas sociais de relacionamento que visam a oferecer, principalmente, dinamismo aos usuários. Assim, podendo contribuir com o sucesso dos resultados esperados por meio da GI realizada com as informações provenientes das MS.

É importante dizer que as MS atraem bastante a atenção dos estudantes e do público em geral, possibilitando que a instituição de ensino adira e ofereça conteúdo informacional de valor ao seu público.

De tal modo, os principais fatores aqui mencionados sugerem as oportunidades do mundo digital em disponibilizar e captar informação de maneira fácil e rápida. As MS atendem satisfatoriamente o empenho da Fatec Garça, que garante, por meio dos funcionários entrevistados, obter retorno com o ingresso de estudantes que conheceram a instituição de ensino por meio das redes digitais.

Em suma, a GI é atributo elementar para as instituições de ensino que utilizam as MS. Gerenciar as informações de maneira inteligente e estratégica proporciona vantagens e agrega mais valor à instituição. Portanto, é de extrema 
importância desenvolver ações voltadas a promover o engajamento do públicoalvo a partir das MS.

Assim, acompanhar as tendências de comunicação social nos dias atuais torna-se um fator de sobrevivência e destaque na sociedade, não apenas com relação às instituições de ensino, mas às organizações de modo geral.

\section{Financiamento}

Coordenação de Aperfeiçoamento de Pessoal de Nível Superior (CAPES). Emerging Leaders in the Americas Program (ELAP). Québec/Canada.

\section{Referências}

CHOO, C. W. A organização do conhecimento: como as organizações usam a informação para criar significado, construir conhecimento e tomar decisões. São Paulo: Editora Senac São Paulo, 2003, 426p.

CURTIS, P. K. Gleaning consumer intelligence from blogs and podcasts. Freepint Newsletter, n. 205, May, 2006.

INOMATA, D. O. ARAÚJO, W. C. O.; VARVAKIS, G. Fluxos de informação na perspectiva organizacional. Informação \& Informação, Londrina, v. 20, n. 3, p. $203-228,2015$.

KHAN, G. F. Seven Layers of social media analytics: Mining Business Insights from Social Media Text, Actions, Networks, Hyperlinks, Apps, Search Engine, and Location. Lexington: 2015.

LAUDON, K.; LAUDON, J. P. Sistemas de Informação gerenciais. São Paulo: Pearson Prentice Hall, 2007.

LAWSON, B.; PETERSON, K. J.; COUSINS, P. D.; HANDFIELD, R. B. Knowledge sharing in interorganizational product development teams: the effect of formal and informal socialization mechanisms. Journal of Product Innovation Management, [S. 1.], v. 26, n. 2, p.156-172, 2009.

LORENTZEN, A. Knowledge networks in local and global space. Entrepreneurship and Regional Development, [S.l.], v. 20, n. 6, p. 533-545, 2008.

NONAKA, I; TAKEUCHI H. Criação de conhecimento na empresa: como as empresas japonesas geram a dinâmica da inovação. Rio de Janeiro: Elsevier, 1997, 29.ed. p.61-82. 
PATEL, N. As 10 Redes Sociais Mais Usadas no Brasil (e no Mundo) em 2018 e 2019, [S.l.]: 2019.

PERREAULT, M. C.; MOSCONI, E. P. Social Media Engagement: Content Strategy and Metrics Research Opportunities. Proceedings of the 51st Hawaii International Conference on System Sciences, Honolulu: 2018.

PERREAULT, M. C. L'engagement des consommateurs envers une marque via les médias sociaux. Dissertação (Mestrado em Ciências) - Université de Sherbrooke), École de Gestion - UdeS, Sherbrooke, Canadá, 2017.

PHELPS, C.; HEIDL, R.; WADHWA, A. Knowledge, Networks, and Knowledge Networks: A Review and Research Agenda, Journal of Management, [S.l.], v. 38, n. 4, 2012.

SARDELARI. Í. M. T. Gestão da informação e do relacionamento com o cliente no contexto do facebook: o caso de uma instituição financeira. Dissertação (Mestrado em Ciência da Informação) - Universidade Estadual Paulista, Faculdade de Filosofia e Ciências - UNESP, Marília, 2017. Disponível em: https://repositorio.unesp.br/handle/11449/150776. Acesso em: 01 maio 2019.

VALENTIM, M. L. P. Gestão da informação e do conhecimento no âmbito da ciência da informação. São Paulo: Polis; Cultura Acadêmica, 2008. 272p.

YIN, R. K. Estudo de caso: planejamento e métodos. 4. ed. Porto Alegre:

Bookman, 2010.

\title{
Information management and social media for student engagement in universities
}

\begin{abstract}
The data and information present in the media can be processed, interpreted and analyzed, identifying metrics that demonstrate the level of user engagement. They can also promote the engagement of current and future students in higher education institutions. So, the research question: what content strategies contribute to social media engagement of current and future students? The overall objective was to identify the most appropriate content strategies for using social media to engage students. The specific objectives are to identify which type of content on social media attracts more attention from the public and investigate measures that allow verifying information on student behavior. This research is did characterize as exploratory and quantitative-descriptive in nature, using the Case Study method by Yin (2010) carried out in a higher education institution in the state of São Paulo, Brazil. The research subjects involve 109 students and 2 employees responsible for social media. A guiding framework was did built from the interrelation of the concepts of information management and social media, generating indicators for the use of social media.
\end{abstract}


The institution's social profile on Facebook has 4932 users and 246 publications for a period of one month. Signs of user engagement were did observe and photo-type publications were found to be the ones with the most involvement. The entrance exam period represents the greatest flow of publications. In addition, $82.6 \%$ of Internet users said they feel closer to the institution.

Keywords: Brazil; Information Management; Media engagement; Social media; Social networks.

Recebido em: 20/10/2020

Aceito em: 06/04/2021

\section{Declaração de autoria}

Concepção e elaboração do estudo: Everaldo Henrique dos Santos Barbosa, Cássia Regina Bassan de Moraes.

Coleta de dados: Everaldo Henrique dos Santos Barbosa, Cássia Regina Bassan de Moraes.

Análise e interpretação de dados: Everaldo Henrique dos Santos Barbosa, Cássia Regina Bassan de Moraes.

Redação: Everaldo Henrique dos Santos Barbosa, Cássia Regina Bassan de Moraes.

Revisão crítica do manuscrito: Everaldo Henrique dos Santos Barbosa, Cássia Regina Bassan de Moraes.

\section{Como citar:}

BARBOSA, Everaldo Henrique dos Santos; MORAES, Cássia Regina Bassan de. Gestão da informação e mídias sociais para o engajamento dos estudantes nas instituições de ensino superior. Em Questão, Porto Alegre, v. 28, n. 2, e108569, abr./jun. 2022. https://doi.org/10.19132/1808-5245282.108569

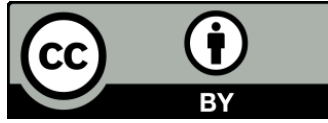

